\section{Lead in petrol}

SIR - Jasper Becker's report (Nature 4 November, p.6) on efforts to persuade the European Community to revise its directive on the lead content of petrol perpetuates a general misunderstanding about the directive by saying that it permits a maximum level of 0.4 grammes of lead per litre of petrol and a minimum of 0.15 , thus implying that petrol with less than 0.15 grammes is not permitted. l.ater the report reinforces this misconception by describing the current campaign to introduce lead-free petrol and saying that "no member state is at present allowed to do this".

In fact the directive does not prevent anyone marketing lead-free petrol. What it does do is to prevent any member state from banning lead in petrol or insisting on any lead level less than 0.15 grammes per litre. Thus if the motor industry and the oil companies could agree, it would be possible for lead-free petrol to bc introduced tomorrow. If, however, member states are to intervenc and insist on lead-free petrol from a certain date they will have to do so simultaneously by agreeing an amending directive.

Another requirement of the directive that deserves to be better known is that the member states have to supply the EEC Commission, at its request, with information on the "development of the concentrations of lead and polluting substances in the urban atmosphere and their effect on public health". The Commission in turn is to report to the Council and Parliament on the information thus obtained and, in the light of the data compiled, is to make appropriate proposals for developing further Community policy on the lead content of petrol. Thus it was foreseen in 1978, when the directive was agreed, that the levels could and should bc changed if new knowledge justified it.

NitiEl HAKiH

Institute for European

Environmental Policy,

London $W \mathrm{l}, \mathrm{UK}$

\section{No contest?}

$\mathrm{SIK}_{\mathrm{K}}-$ Nature is highly valued by the scientific community not only for its scientific content, but also for its unwavering position on matters of scientific moral behaviour - and last but not least, the standing of its advertisments. Therefore I would like to draw your attention to an instance which I consider as reprehensible practice, in which, in this case, Nature has been unwittingly the vehicle.

In Nature Vol. 285, 26 June 1980, the Malaysian government announced (page xxvii) a world-wide competition to find a speedy and accurate method of determining the dry rubber content (DRC) of latex. I sent an entry to this contest on 18 December 1980.

A letter of the Malaysian Rubber Research and Development Board (MRRDB), dated 3 March 1982 stated: ". . . [we] regret the delay in the final judging; this has been due to the good response [63 entries, note $M . B$. ] received and the need to test out some of the entries".

Without news for several months from the MRRDB, I wrote them a fetter on 26 October 1982 , from which I quote: "I presume this final judging has taken place. Sincere scientific curiosity, besides the sportsmanship of having participated, prompts me to ask the communication of the optimal method having been selected. Perhaps it could be published. ..'

From the answer of the MRRDB (10 November 1982): "Judging of the Dry Rubber Content determination competition took place on 28 October 1982 and regretfully, of the 63 entries received from all over the world, including the one entered by you, there has been no outright winner as none of the entries met the criteria of an ideal method for DRC determination."

Conclusion: for the price of an advertisment - and the vague promise of the sum of about $\$ 10,000$, which is a mere trifle as research budgets go - the MRRDB did perhaps not obtain the dream-method, but it may be estimated that a significant fraction of the entries yielded enough valuable ideas, elements and propositions to obtain, through very little further expense, the ideal method, provided that one exists. Really, the MRRDB got quite cheaply a great deal of intellectual effort.

Had the advertisment in question appeared anywhere else than in Nature, I at least, and perhaps more of the 62 colleagues who sent entries would have perceived beforehand the unilaterality and the arbitrariness behind such a "contest".

MICHEI M. BENARII

\section{Institut National de Recherche Chimique Appliquée, \\ Bretigny, France}

\section{Vitamin $\mathbf{C}$ reviewed}

SIR - In reviewing our book "Vitamin C in Health and Disease" (Nature 299, 760), Dr Rivers has had to contend with the problem of assessing three books at once and the selfinflicted difficulty of having apparently prejudged the debate on vitamin C. Rivers's view appears to be that the vitamin's only function in man is to prevent the symptoms of overt clinical scurvy. He may be right, but as we emphasize this possibility in the concluding paragraph of our book, it is surprising that he accuses us of having an "atrophied critical faculty". However, he apparently draws this conclusion from a series of comments about the book which are simply not true, and it is these I wish to refute.

He does not exclude our book from his general observation that all three texts claim that vitamin $C$ will not only cure scurvy but colds, cancer and cardiovascular disease. We make no such claim. We include in our evidence on vitamin $\mathrm{C}$ and the common cold the statement that randomized, blind, clinical trials have indicated that megadose vitamin C therapy has almost no effect on either the frequency or length of the cold. However, there is some evidence that there are decreases in the severity of the symptoms. For cardiovascular disease and cancer, we suggest that although vitamin $\mathrm{C}$ deficiency may be implicated in the aetiology of these conditions, only long-term, large-scale, randomized, controlled trials can confirm or refute such roles for the vitamin.

Rivers makes a more detailed criticism of one section of the book and again he is in error. In the figure he refers to, there is both a highly significant difference between the two groups and a significant correlation in one of the groups alone, a finding that he was unable to see by eye. To us, this indicates an association between hepatic vitamin $\mathrm{C}$ and rate of cholesterol transformation, without suggesting that a cause and effect relationship has been proven. The section which includes this graph makes no claim, as Rivers states, that changes in vitamin $C$ status are central to fluctuation in mortality from ischaemic heart disease. Indeed, we warn that such evidence is only circumstantial and indirect.

In our book on vitamin $C$ in health and disease we have attempted to summarize the available evidence. Dr Rivers may honestly feel that we have leant too far towards those who support a role for vitamin $\mathrm{C}$ in the prevention of a whole variety of diseases and he is entitled to his opinion, but he should have supported his views by statements which are correct.

C.J. SCHORAH

Department of Chemical Pathology,

University of Leeds,

Leeds, UK

\section{Jungle law}

$\mathrm{SiR}-\mathrm{J}$. Fleuris (Nature 18 November, p.212) is correct in stating that orang is Malay for man (though person is more accurate, as orang has no sense of gender), but orang utan has orang-utan only as a secondary meaning. Its literal meaning is man (or person) of the jungle (utan being the common word for jungle, as opposed to $u l u$ which means upriver and has come to mean jungle by extension)

J.R. G(SDL:N

Eskbank, Midlothian, UK

\section{Chinese names}

Sik - M.C. Mckenna (Nature 18 November. p.212) oversimplifies when he states that Chinese given names are now hyphenated and the second syllable is not capitalized in English transliteration. While the use of the hyphen to link given names is widespread, it is by no means universal and the use of a capital for the second syllable is at least as common as lower-case.

Morcover it is now common in journals from Mainland China for the given names to be written as one word, for example Chen Yurong. This practice still enables the surname (usually one syllable) to be distinguished easily from the given names (usually two syllables) but the single-syllable given name (such as Pei, in Wang Pei) may still cause difficulty. It is not unknown, either, for "helpful" journals from Chinese and other idcographic language sources to present transliterated names in a Western order, without an obvious indication of their praclice.

$$
\text { SISAN JEIIIS }
$$

Commonwealth Bureau of Plant Breeding and Genetics, Cambridge, UK 